\title{
Impact of Internet of Things (IoT)'s Service Quality on the Hotel Customer Satisfaction
}

\author{
Dong-Heui Choi
}

\begin{abstract}
The objective of this study is to use service based on Internet of Things identifying whether service quality based on Internet of Things perceived by customers significantly influence on customer satisfaction and provide implications on them. For this, survey was used to collect data for practical analysis. Survey was conducted for 47 days from September 3 to October 19, 2018. Total 250 copies were distributed, and 238 of them were collected. Among them, after excluding 22 copies with imperfect responses, 216 copies were used for practical analysis. It affects customer satisfaction in the order of firmness, reliability, empathy, usability, and responsiveness. At the same time, the confidence in the system of Internet of Things and the question of the system were the most important factors in the satisfaction of the hotel staff. This was how this study was differentiated from other researches dealing with customer satisfaction in the field of hotel. This was because it was necessary to accurately resolve the unfamiliarity and maladjustment of customers' Internet-based services as they are still in the beginning phase as they are able to understand customers by accurately communicating information about services based on the Internet. Efforts shall also be made by employees to accurately notifying the results from inquiries.
\end{abstract}

Keywords : Internet of Things (IoT), Service Quality, Customer Satisfaction

\section{INTRODUCTION}

A new paradigm emerged with a rapid development of information communication and digital technology has collapsed the concept of time and space while bringing about a new paradigm in each field of society. Using a smart phone as a personal medium, people are able to be connected with others, groups, data, contents, and digital devices at any time and place. Without restriction on location and time, people are able to interact with others on a real-time basis with an increasing scope of subjects to be connected [1]. Among them, Internet of Things (IoT) has been receiving much attention as a core technology in the future incorporating things used by people and providing efficiency and convenience to lives of humans. At the same time, it is expected that things are connected with each other without or with a minimum involvement of humans through Internet generating, collecting, sharing, and utilizing information in a system environment. Such an environment is called as Internet of Things (IoT) [2]. It is possible to create a new business with Internet of Things while making it feasible to define relations of things as a process or apply various technologies such as automatic use of technology through the

Revised Manuscript Received on July 22, 2019.

Dong-Heui, Choi*, Professor, Dept. of Hospitality \& Tourism Management, 277 Hyodeokro, Namgu, Gwangju, 503-703, Korea, Email: cdhyes@gwangju.ac.kr pattern-oriented learning. Therefore, it is possible to make many of the changes in human lives. With information technology related to them, there is a prospect that 50 billion objects in the world can be connected in Internet. Among such predictions 1) Internet of Things will be naturally formed in human lives while providing new values to humans [3]. Internet of Things is eventually referred to as an integration of data through the incorporation of complicated technologies. In addition, it is expected that Internet of Things will change information communication and industrial infrastructure with various types of technologies including the sensor, actuator, and user device and network technologies [4]. In hotels, service based on Internet of Things has been adopted. Using smart tags, people are able to access hotels or various security facilities only by possessing smart tag. At the same time, it is possible to pay for service including the medical and health information management or post-payment in business areas in a hotel for senior tourists while utilizing wireless handy home system in a room to control the opening of a door for visitors or various media and environments in a room. These are all provided by the service of Internet of Things to users. However, there has not been a study in dealing with customer awareness of service quality based on Internet of Things in a hotel. Therefore, the objective of this study is to use service based on Internet of Things identifying whether service quality based on Internet of Things perceived by customers significantly influence on customer satisfaction and provide implications on them. Therefore, this study has theoretically considered how variables related to service quality and customer satisfaction were suggested in previous related studies to prepare for theoretical foundation to identify characteristics and relations of each variable and propose theoretical hypotheses for the practical analysis as an assumption for deductive verification. With the objective of this study, it is expected to identify cause-and-effect relationship between service quality based on Internet of Things at a hotel and customer satisfaction and help understand a desirable direction of adoption and operation of Internet of Things service and operation for hotel management in the future.

\section{LITERATURE REVIEW}

\section{Internet of Thing(Iot)}

Internet of Things can be defined as an intellectual environment where information is exchanged and interacted between human and object or between objects in connection with wire/wireless network on all the things around people based on ICT [5]. 
As a professional market investigating organization in America, Gartner has chose Internet of Things as one of the 10 strategic technologies that can significantly influence on human lives in the future and is prospecting how 100 billion objects and smart devices will be connected with APP until 2020. Furthermore, Internet of Things saves collected big data in the cloud utilizing artificial intelligence for the analysis. Therefore, it is now in a limelight as a core technology in the fourth industrial revolution and also as a pivotal technology to realize how people become eligible to enter smart world [6]. Major issues in the researches related to Internet of Things are about 'how to integrate information protocol and data standards that are different among various devices.' The more there has been an attempt to incorporate sensing technology on various objects and utilize them as Internet of Things, the more it has become important to exert an effort to integrate communication protocols and data formats among different systems of diverse objects and inter-operate them together along with an increasing case of utilizing them as an open service [7]. As for 7successful cases, tour information service has emerged in the use of smart phone based on Internet of Things in tour organizations such as travel agencies, airlines, and hotels from local communities in Seoul. 'Korea Here and There,' the tour information smart application from Korea Tourism Organization, has been playing a leading role to promote domestic traveling [8]. In addition, I-tour Seoul is an application for tour guide provided by the city of Seoul and also an IT-based tour convenience service that is downloadable by tourists from Korea and abroad from online application store in the use of smart phone and website without renting separate device. With this application, people are able to collect various information in the city of Seoul planning the trip. At the same time, this application makes it feasible to automatically identify appropriate tour information and current location for users commercializing the routing service to the destination with various map services along with public traffic information near the place [9].

\section{Service Quality}

The concept of service quality can be interpreted in various meanings depending on the perspective and approaches. Service quality is classified into four elements. With characteristics including intangibility, difference, non-separability, and extinction, it is very difficult to measure the service quality meaning how service quality is more of subjective evaluation perceived by customers who experience service in person over the clarification in the use of objective criteria [10]. Service quality is referred to as a degree of inconsistency between expectation on the customer service provided by a company and the service provided and perceived by customers. Service quality relies on intangible clues and is regarded as an assessment of customers on superiority and overall outstanding features of the service [11]. In order to confirm the disparity of perception of tourists and hotel managers, a research was conducted in the use of about 35 hotel service quality characteristics. In this study, it was confirmed that overall service quality provided by hotel industry in China turned out to be less than expectation of tourists. The biggest difference between expectation and perception of tourists was related to 'physical facility,' 'skill and performance of employees,' and 'price and value.' [12]. On the other hand, as for important factors influencing on the customer satisfaction, there were reception, cleanliness, food and beverage, and price. In other words, all the aspects in the operation of hotel was concluded not to be equally important for customers. Customer satisfaction on the cleanliness turned out to be the one and only meaningful factor to determine loyalty of customers. Reception, food and beverage, and price were regarded to be a supportive factor when determining the revisit, recommendation, or loyalty for a specific hotel [13]. In a study conducted with two major service quality criteria in the luxury hotel service evaluation in Korea (overall room value and front service), seven categories of cleanliness, atmosphere, convenience, quality, sufficiency of room parts, size of rooms, availability of free items, and price were provided for the overall values of rooms. On the other hand, front service was divided into seven features including the responsiveness such as convenience of the reservation, swiftness of check-in or -out, provision of information for hotel or tour guide, types of sport or leisure facilities with good quality (swimming pool, or aerobic room), and business space efficiency (fax, PC, or copy machine) [14]. Juwaheer \& Ross (2003) [15] indicated that evaluation of overall service quality of a hotel was as followed. First of all, firmness was t related to immediate and efficient problem solving or complaint-handling by hotel employees as well as safety and security of customers. Secondly, reliability was to solve imminent issues of customers while performing tasks promised with customers.

\section{Customer Satisfaction}

Customer satisfaction is the final outcome from evaluation procedures of a customer based on the results of purchasing behaviors of consumers. In addition, customer satisfaction is a feedback on customer evaluation and, hence, is determined ultimately according to psychological satisfaction from expectation of a consumer. If fulfilling expectation from necessity and demand from a customer or even achieving a higher level above original expectation, customers tend to be satisfied. If not, they are dissatisfied according to the definition of customer satisfaction [16]. As for research models mostly used in a research in dealing with customer satisfaction, there is an expectation-inconsistency model [17]. According to expectation-inconsistency model, negative inconsistency was perceived when perceived performance turned out to be short of standards when setting the expectation as a criterion for the analysis. At the same time, consistency was achieved when expectation was equivalent with perceived performance. If perceived performance was lower than the expectation, positive inconsistency was achieved. Therefore, expected-inconsistency turned out to play a pivotal role to determine whether customers were satisfied [18]. On the other hand, it was criticized how researches conducted on the customer satisfaction so far through the re-evaluation of customer satisfaction determining factors focused on the paradigm of expectation and inconsistency while applying new conceptual models and suggesting characteristic and information-oriented satisfaction related to customer 
satisfaction [19]. As for the formation of purchasing intent, it was indicated by researches dealing with the relationship between service quality and customer satisfaction that service quality influenced on customer satisfaction and, in turn, led to the purchasing intent [20].

\section{PROPOSED METHODS THE TEMPLATE}

This study was intended to identify how service quality based on Internet of Things perceived by customers influenced on the customer satisfaction in the use of service according to Internet of Things in hotels. For this, survey was used to collect data for practical analysis, and survey was comprised of three main areas including service quality based on Internet of Things, customer satisfaction, and demographic variables. To be specific for the survey contents, first of all, it was to measure service quality. After modifying them to be appropriate for this study based on other previous researches, 15 questions were selected. Second part was to measure dependent variable and was comprised of six items to measure customer satisfaction as a dependent variable. Third part was comprised of six items to confirm demographic variables. Survey was conducted on hotel users where the service based on Internet of Things was provided to. In order to provide enough explanation about the intent of this study and how to acquire survey, each of the hotel concierges or front employees was chosen and distributed. Survey was conducted for 47 days from September 3 to October 19, 2018. Total 250 copies were distributed, and 238 of them were collected. Among them, after excluding 22 copies with imperfect responses, 216 copies were used for practical analysis. In order to accomplish the goal of this study, practical analysis was conducted by using SPSS Ver.21 with valid samples collected from the survey. As for analytical methods used for the analysis, there were frequency analysis, reliability analysis, factor analysis, and multiple regression analysis.

\section{RESULTS AND DISCUSSION}

For the demographic characters on 216 respondents collected from the survey, frequency analysis was conducted. A s a result, there were 112 men $(51.7 \%)$ and 104 women $(48.3 \%)$. At the same time, there were 87 subjects aged in the $40 \mathrm{~s}(40.1 \%), 64$ subjects in their $30 \mathrm{~s}$ (29.7\%), and 40 subjects in their $50 \mathrm{~s}(18.8 \%)$. As for academic background, there were 156 subjects $(72.1 \%)$ as college graduates. As for job, there were 76 subjects $(35.2 \%)$ who were office workers, 41 experts (19.2\%), and 39 self-employed subjects (18.0\%). As for monthly average household income, there were 64 subjects with less than 4 to 5 million Won $(28.8 \%)$ followed by 60 subjects less than 3 to 4 million (27.9\%) and 45 subjects (21.1\%) less than 4 to 5 million Won. As for nationality, there were 46 Korean subjects $(21.2 \%)$ followed by 44 Chinese subjects (20.5\%), 36 Japanese subjects (16.5\%), and 20 American subjects $(9.3 \%)$.

In order to estimate the reliability on the service quality based on Internet of Things in hotels, exploratory factory analysis was conducted on 15 questions. Results are shown in $<$ Table 1>. According to results of analysis on the service quality, there were five factors with eigenvalue exceeding 1.0, and accumulated dispersion value was over $60 \%$ showing that results of factor analysis were fairly valid. In addition, KMO (Kaiser-Meyer-Olkin) value turned out to be high as 0.866 , and the Approximate Chi-Square value of Bartlett turned out to be significant as $\mathrm{p}=.000$. Therefore, samples in this study turned out to be very appropriate to apply factor analysis. According to results of service quality based on Internet of Things in hotels, five factors of firmness, reliability, responsiveness, usefulness, and empathy were derived.

Table- I 1: Factor Analysis and Reliability Analysis of Service Quality

\begin{tabular}{|c|c|c|c|}
\hline $\begin{array}{l}\text { Factor } \\
\text { name }\end{array}$ & Metrics & $\begin{array}{l}\text { factor } \\
\text { loading }\end{array}$ & $\begin{array}{l}\text { Cron } \\
\text { bach' } \\
\text { s } \alpha\end{array}$ \\
\hline $\begin{array}{l}\text { Usefulness } \\
\quad(6.011 \\
21.782)^{1)}\end{array}$ & $\begin{array}{c}\text { Convenient route } \\
\text { Service constitution } \\
\text { Consistent configuration } \\
\text { Convenient awareness }\end{array}$ & $\begin{array}{l}.814 \\
.780 \\
.756 \\
.709\end{array}$ & .847 \\
\hline $\begin{array}{l}\text { Reliability } \\
(3.232 \\
12.046)\end{array}$ & $\begin{array}{l}\text { Update with up-to-date information } \\
\text { Provide accurate information } \\
\text { Safe on the usage }\end{array}$ & $\begin{array}{l}.816 \\
.810 \\
.785\end{array}$ & .846 \\
\hline $\begin{array}{c}\text { Responsive } \\
\text { ness } \\
(2.022 \\
10.321)\end{array}$ & $\begin{array}{l}\text { Swift system } \\
\text { Accurate information delivery } \\
\text { Fast response on the requirements }\end{array}$ & $\begin{array}{l}.719 \\
.714 \\
.688\end{array}$ & .771 \\
\hline $\begin{array}{l}\text { Firmness } \\
(1.846 \text {, } \\
9.369)\end{array}$ & $\begin{array}{l}\text { Reliability on the system } \\
\text { Accurate response from the } \\
\text { employees }\end{array}$ & $\begin{array}{l}.822 \\
.778\end{array}$ & .812 \\
\hline $\begin{array}{l}\text { Empathy } \\
(1.571 \\
8.368)\end{array}$ & $\begin{array}{l}\text { Provision of requested information } \\
\text { Reflect customer demand } \\
\text { Fulfill customer demand }\end{array}$ & $\begin{array}{l}.815 \\
.720 \\
.681\end{array}$ & .732 \\
\hline
\end{tabular}

1) (Eigen value, variance explanation power)

In order to measure customer satisfaction in the use of service based on Internet of Things in hotels, exploratory factory analysis was conducted on six questions. Results are shown in <Table 2>. According to the results of analysis on the customer satisfaction, a single factor where eigenvalue was over 1 was derived, and the factor was named as customer satisfaction. Accumulated analysis value was 61.003 showing how results of factor analysis were valid. Two items that were not statistically appropriate were removed.

Table- $\Pi$ : Factor Analysis and Reliability Analysis of Guest Satisfaction

\begin{tabular}{c|c|c|c}
\hline $\begin{array}{c}\text { Factor } \\
\text { name }\end{array}$ & Metrics & $\begin{array}{c}\text { factor } \\
\text { loading }\end{array}$ & $\begin{array}{c}\text { Cronba } \\
\text { ch's } \alpha\end{array}$ \\
\hline \hline & & & \\
Customer & Overall satisfaction on the service & .787 & \\
satisfaction & Satisfaction on check-in/out & .784 & .908 \\
$(2.931$, & Satisfaction on the room care & .778 & .749 \\
$61.003)^{1)}$ & Satisfaction on the payment service & .749 & \\
\hline
\end{tabular}

1) (Eigen value, variance explanation power)

In order to clarify the influence of service quality based on Internet of Things in the hotels, multiple regression analysis has been conducted. Results are shown in $\langle$ Table 3. $>$. These results indicate that $\mathrm{F}$ value was 98.401 when $\mathrm{p}$ was equal to .000 , and explanatory power of the regression formula turned out to be $66.3 \%$. In addition, all the usefulness, reliability, 
responsiveness, firmness, and empathy among service quality factors turned out to positively influence on the customer satisfaction. At the same time, firmness turned out to be the most influential among service quality factors.

Table 3: Influence of type of Service Quality to Guest Satisfaction

\begin{tabular}{c|c|c}
\hline \multirow{2}{*}{ Service quality } & \multicolumn{2}{|c}{ Customer satisfaction } \\
\cline { 2 - 3 } & $\begin{array}{c}\text { Standardization regression } \\
\text { coefficient }\end{array}$ & t-value \\
\hline \hline sefulness & .091 & $2.921^{* *}$ \\
\hline Reliability & .292 & $9.398^{* *}$ \\
\hline Responsiveness & .062 & $2.005^{*}$ \\
\hline Firmness & .741 & $23.876^{* *}$ \\
\hline Empathy & .127 & $4.109^{* *}$ \\
\hline \multicolumn{2}{c|}{$\mathrm{R}^{2}=.663$, Adjusted $\mathrm{R}^{2}=.656, \mathrm{~F}=98.401^{* *}$} \\
\hline
\end{tabular}

\section{CONCLUSION}

The purpose of this study is to analyze the relationship between perceived service quality and customer satisfaction by introducing Internet-based service. The implications are as follows. First of all, the academic implications of this study are as follows. This study is differentiated from other researches showing the influence and satisfaction of hotels in that the concept of the Internet of Things has been gradually expanded in the field of hotels, and the influence of service quality and customer satisfaction on the Internet of things have been examined to enhance services has been examined. At the same time, the practical implication of this study is that the latest trends of the internet are applied to the scope of service oriented hotel industry examining how the service quality of Internet of Things has influenced on the customer satisfaction. This was how this study was differentiated from other researches dealing with customer satisfaction in the field of hotel. Next, practical implications are as follows. First of all, it affects customer satisfaction in the order of firmness, reliability, empathy, usability, and responsiveness. At the same time, the confidence in the system of Internet of Things and the question of the system were the most important factors in the satisfaction of the hotel staff. This was because it was necessary to accurately resolve the unfamiliarity and maladjustment of customers' Internet-based services as they are still in the beginning phase as they are able to understand customers by accurately communicating information about services based on the Internet. Efforts shall also be made by employees to accurately notifying the results from inquiries. This study is limited in measuring the service quality by applying the Internet of objects in the hotel. However, the limited sample extraction and the generalization error may be due to the small number of service operating hotels based on the Internet. At the same time, the Internet of things is still in the beginning phase. It is difficult for customers to understand the services of Internet based services due to the lack of understanding and adaptation. Therefore, it is necessary to utilize various types of data gathered through the Internet to analyze diverse yet high customer needs for the future research, and to study the management performance through such factor analysis.

\section{APPENDIX}

It is optional. Appendixes, if needed, appear before the acknowledgment.

\section{ACKNOWLEDGMENT}

This Study was conducted by research funds from Gwangju University in 2019.

\section{REFERENCES}

1. J. H. Lee, S. H. Cho, "Study of Relation Between Consumers" Advertisement Attitude and Need for Cognition for IoT-Implemented Advertisement" Journal of Digital Contents Society. 16(1), 165-172, 2015. https://doi.org/10.9728/dcs.2015.16.1.165

2. D. Wang, S. Park, D. R. Fesenmaier, "The role of smart phones in mediating the touristic experience" Journal of Travel Research. 51(4), 371-387. 2013. https://doi.org/10.1177/0047287511426341.

3. D. H. Sin, J. Y. Jeong, S. H. Kang, "Internet of Things Trends and prospects" Korea Society for Internet Information. 14(2), 32-46. 2012. http://210.101.116.16/kiss61/download_viewer.asp

4. C. E. Parck, "A Study on effects of distribution changes on Internet of Things" Korea Logistics Review. 24(3), 151-174. 2014. http://scholar.dkyobobook.co.kr.eproxy.sejong.ac.kr/searchDownload.1 af? barcode $=4010023843076 \& \operatorname{artId}=10121105 \& \mathrm{gb}=$ pdf \& $\mathrm{rePdf}=$ pdf

5. W. S. Jeong, S. H. Kim, K. S. Min, "An Analysis of the Economic Effects for the IoT Industry" Journal of Internet Computing and Services. $15(5), \quad 119-128$. https://doi.org/10.7472/jksii.2013.14.10.119.

6. H. Y. Cha, D. S. You, "Study on the audience effect of advertisements of IoT products across different levels of sensory innovativeness" Journal of Digital Convergence. 16(5), 145-152. 2018 https://doi.org/10.14400/JDC.2018.16.5.145.

7. M. K. Jung, S. Y Kwon, "A Study on Internet of Things based on Semantic for Library" Journal of Korean Library and Information $\begin{array}{llll}\text { Science } & \text { Society. } & 45(2), & 235-260 .\end{array}$ https://liss.jams.or.kr/po/volisse/sjPubsArtiPopView.kci?soceId=INS00 0000015\&artiId=SJ0000001043\&sereId=SER000000001\&submCnt= 1

8. W. H. Kim, "Research on the Satisfaction degree with Tourism Informations for Smartphone users and revisitation intention : Forcusing on the tourist attractions in Gangneung" Journal of Hotel \& Resort. 13(3), 411-433. 2014 http://www.earticle.net.ssl.eproxy.sejong.ac.kr/Article/A244331

9. S. J. Han, "The Effects of Self-Efficacy, Satisfaction and Reuse Intention on Adoption of Internet of Things - Based on Culture Tourism Information Service Users' Evaluation" Journal of Hotel \& Resort. 15(1), 91-112. 2019 http://www.earticle.net.ssl.eproxy.sejong.ac.kr/Article/A263542

10. V. A. Zeithaml, A. Parasuraman, A. Malhotra, "Service quality delivery through web sites: A critical review of extant knowledge" Academy of Marketing Science Journal. 30(4), 362-375. 2002. https://link.springer.com/article/10.1177/009207002236911

11. N. Kano, "Service Quality (Servqual) and its Effect on Customer Satisfaction in Retailing Introduction -Measures of Service Quality" European Journal of Social Sciences. 16(2), 239-251. 2010 https://www.researchgate.net/publication/267989820_Service_Quality _Servqual_and_its_Effect_on_Customer_Satisfaction_in_Retailing_In troduction_-Measures_of_Service_Quality.

12. N. Tsang, H. L. Qu, "Service quality in China's hotel industry: A perspective from tourists and hotel managers" International Journal of Contemporary Hospitality Management. 12(5), 316-326. 2000. https://doi.org/10.1108/09596110010339706. 
13. J. Kandampully, D. Suhartanto, "Customer loyalty in the hotel industry: The role of customer satisfaction and image" International Journal of Contemporary Hospitality Management. 12(6), 346-351. 2000. https://doi.org/10.1108/09596110010342559.

14. H. Min, H. Min, "Benchmarking the quality of hotel services: managerial perspectives" International Journal of Quality \& Reliability $\begin{array}{lll}\text { Management, } & 14(6), & 582-597 .\end{array}$ https://doi.org/10.1108/02656719710186209

15. T. D. Juwaheer, D. L. Ross, "A study of hotel guest perceptions in Mauritius" International Journal of Contemporary Hospitality Management. 15(2), 105-115. 2003 https://doi.org/10.1108/09596110310462959

16. K. O. Huh, "Evaluation of consumer life by consumers' purchase behavior style" Korean Family Resource Management Association. 9(1), 95-111.

http://www.earticle.net.ssl.eproxy.sejong.ac.kr/Article/A19160

17. H. L. Jo, M. K. Kim, "An Effect of Service Quality on Customer Satisfaction and Loyalty in the Case of Mid-Price Hotel: Application of Quality Classification Based on Kano Model" Korean Journal of $\begin{array}{llll}\text { Tourism } & \text { Research. 32(6), 335-353. }\end{array}$ https://doi.org/10.21719/IJTMS.32.6.17

18. G. A. Churchill, C. Suprenant, "An investigation into determinants of customer satisfaction" Journal of Marketing Research. 19(4), 491-504. 1982. https://doi.org/10.1177/002224378201900410

19. R. A. Spreng, R. D. Mackoy, "An empirical examination of a model of perceived quality and satisfaction" Journal of Marketing. 72(2), 201-214. 1996. https://doi.org/10.1016/S0022-4359(96)90014-7

20. J. Bloemer, K. D. Ruyter, M. Wetzels, "Linking perceived service quality and service loyalty: a multi- dimensional perspective" European Journal of Marketing. 33(11/12), 1082-1106. 1999. https://doi.org/10.1108/03090569910292285

\section{AUTHORS PROFILE}

DONG-HEUI CHOI received his Ph.D. in Hotel Tourism Management from Sejong University and is currently a professor in the School of Hotel \& Tourism Management at Gwangju University. His research interests are hotel management and human resource management 